\title{
Surgical management of chronic fourth degree perineal tear: a single center experience
}

\author{
Ramesh Kumar R., Seema Chigateri*, Leena Kamat, Divya
}

Department of Obstetrics and Gynecology, SDM Hospital, Dharwad, Karnataka, India

Received: 16 September 2018

Accepted: 22 October 2018

\section{*Correspondence:}

Dr. Seema Chigateri,

E-mail: seemachigateri@yahoo.com

Copyright: (C) the author(s), publisher and licensee Medip Academy. This is an open-access article distributed under the terms of the Creative Commons Attribution Non-Commercial License, which permits unrestricted non-commercial use, distribution, and reproduction in any medium, provided the original work is properly cited.

\begin{abstract}
Background: The aim of this article is to present the ridge about the recognition, preoperative management, surgical technique and long term follow up of patients with chronic fourth degree perineal tear.

Methods: Authors conducted a prospective study in the department of obstetrics and gynecology in SDM hospital of medical sciences from 2008 January to 2016 December. Data on age, parity, incontinence to flatus, solid or liquids stools, duration of symptoms, history of previous repair, duration of repair, post-operative stay, complications and recovery were collected and analyzed. A total of thirty cases of chronic perineal tear were studied.

Results: A total of 30 patients underwent CPT repair. Average duration of surgery was 90 minutes. 27 out of 30 patients were discharged on post-operative day 10. Three patients were non-compliant to treatment. Of the total 30 patients, two patients were lost for follow up. Overall success rate was $93 \%$ including patients who underwent resurgery for failed repair.

Conclusions: The significant finding of the present study was that a secondary repair of an anal sphincter injury was not associated with an unfavorable subjective outcome in relation to symptoms of anal incontinence. A good insight of perineal and anal sphincter anatomy and adherence to the sound principles is essential. The success rate in this study is $93.3 \%$ highlighting that a diligently performed operation by a surgeon of adequate expertise likely results in satisfactory outcome.
\end{abstract}

Keywords: Anal sphincter, Complete perineal tear, Secondary repair

\section{INTRODUCTION}

Perineal lacerations are within the scope of knowledge since the time of Hippocrates. Perineal stitching following childbirth was endorsed in ancient writing of "midwifery and obstetrics", however the procedure was not routinely performed. They involve a tear in the vagina, skin, muscles between the vagina and anus and anal sphincter. Chronic complete perineal tear can have a significant impact on women's emotional and physical health. Patient can present with wide range of symptoms including fecal incontinence, passive soiling or incontinence of liquid or solid stool. Few women can even experience fecal urgency. Anal sphincter rupture is reported in about $2.5 \%$ of vaginal deliveries in centers that practice mediolateral episiotomies and $11 \%$ in centers that practice midline episiotomy. ${ }^{1,2}$ Around 3$10 \%$ of women after childbirth suffer from fecal incontinence. $^{3}$

Women feel awkward and are not always communicative with symptoms of anal incontinence or some may assume that the symptoms are a result of normal vaginal delivery. It can add onto financial affliction to the woman in terms of usage of pads, frequent hospital appointments and work absenteeism. 
Neglected or missed tears or faulty repair may also present an inherent source for litigation. The aim of this study was to evaluate the effectiveness, long term followup and to highlight the current practices regarding secondary repair of chronic fourth degree perineal tear.

\section{METHODS}

Thirty consecutive cases of chronic perineal tears were selected from department of obstetrics and gynecology, SDM college of medical sciences and hospital, Dharwad, Karnataka, India from January 2008 to December 2016. Data were collected prospectively on age, parity, incontinence to flatus, solid or liquids stools, duration of symptoms, history of previous repair, duration of repair, post-operative stay, complications and recovery.

Counseling-Patients considering for perineal tear repair were meticulously informed about their chances for a successful functional sequel after surgery.

\section{Preoperative management}

Bowel preparation -Although there is no evidence-based guideline for a preoperative bowel regimen before anal surgery, tablet bisacodyl 10mg was given on the previous day of surgery. Bowel preparation was done before sphincter repair to decrease bacterial contamination of the perineal wound.

Antibiotics -Preoperatively, patients were administered with intravenous ornidazole $500 \mathrm{mg}$ and ceftriaxone $1 \mathrm{gm}$ stat was given, that covers skin and enteric flora.

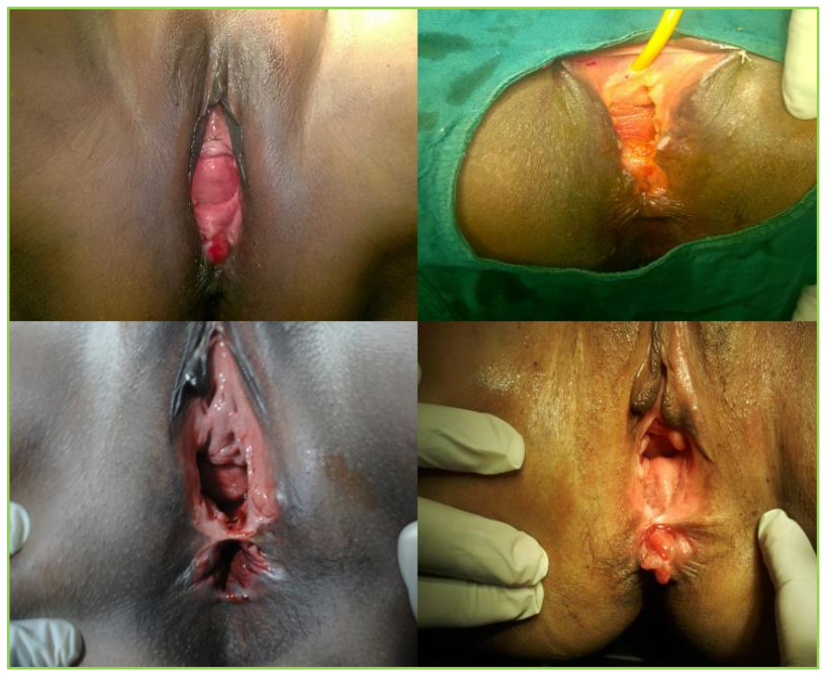

Figure 1: Grossly deficient perineum with absence of anal puckering around the anterior aspect of anus at 3 and 9'0 clock position.

\section{Surgery}

Anesthesia-All the patients underwent CPT repair under regional anesthesia.
Foley catheter-A Foley catheter is placed before the procedure. The Foley catheter is typically left in overnight and removed the morning after surgery because pain from the anal surgery often inhibits spontaneous voiding.

Positioning-Patients were positioned in dorsal lithotomy.

Surgical goals-The goal of sphincter repair was to reconstruct a cylindrical anal canal utilizing both external sphincter muscle and perineal body scar, to allow circumferential contraction of the anal musculature when the patient attempts to defer defecation.

\section{Procedure}

On either side of the lower edge of labia minora, two lateral ends of rectovaginal septum are held with Allis tissue forceps (Figure 2). Postero-laterally over the dimple, two more Allis are applied representing the torn edges of external anal sphincter. Along the junction of posterior vaginal wall and rectal mucosa an elliptical incision is made extended postero-laterally over the dimple.

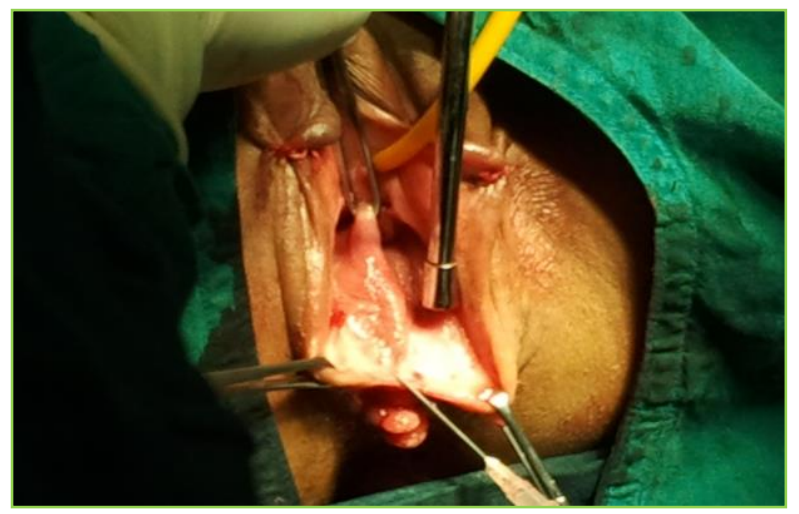

Figure 2: The vaginal and rectal walls are separated from each other by dissection to the levator ani complex.

Sharp dissection is done to separate anterior wall of rectal mucosa from posterior vaginal wall creating a good rectovaginal space. Incision is deepened over the dimple to expose the torn ends of EAS (Figure 3) and are held with Allis tissue holding forceps to feel the tightness of the sphincter. Two main aspects of sphincter repair are the removal of scar tissue, identifying the torn edges of EAS and the mobilization of rectum. Anorectal mucosa is repaired with 3-0 continuous polyglactin 910 suture to reach the mucocutaneous junction of the anal opening.

Internal anal sphincter: The IAS is identified, repaired separately from the EAS. The IAS lies between the EAS and the anal epithelium. It is thinner and paler than the striated EAS. The appearance of the IAS can be described as being analogous to the flesh of raw fish, as opposed to the red meat appearance of the EAS. Ends of the IAS are 
identified and sutured with 3-0 polygalactin 910 (Figure 4). The torn ends of the EAS is freshened then be overlapped in a "double-breasted" fashion using 3-0 Polyglactin 910. A proper overlap is possible only when the full length of the torn ends of the EAS is identified.

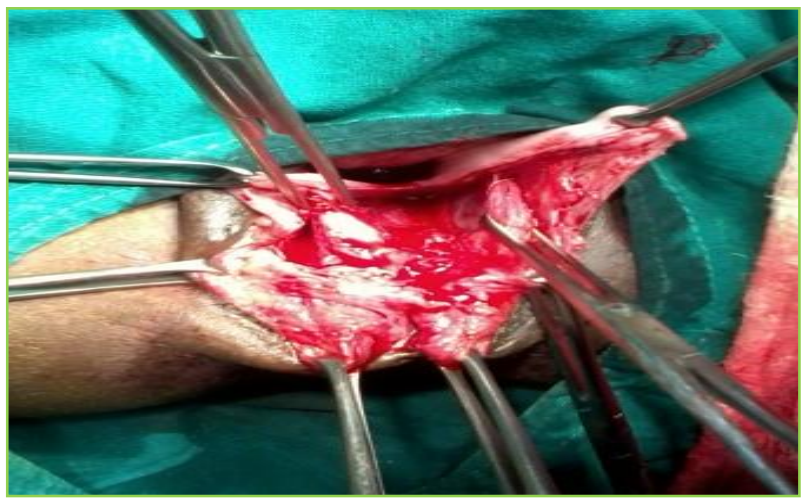

Figure 3: The scar and the external sphincter muscles are carefully freed from the internal sphincter to allow the left and right external sphincter and scar complexes to overlap anteriorly.

Perineal body reconstruction: The two levator ani muscles are drawn together in between the posterior vaginal wall and anterior wall of the rectum and anal canal is sutured with interrupted 3-0 vicryl.

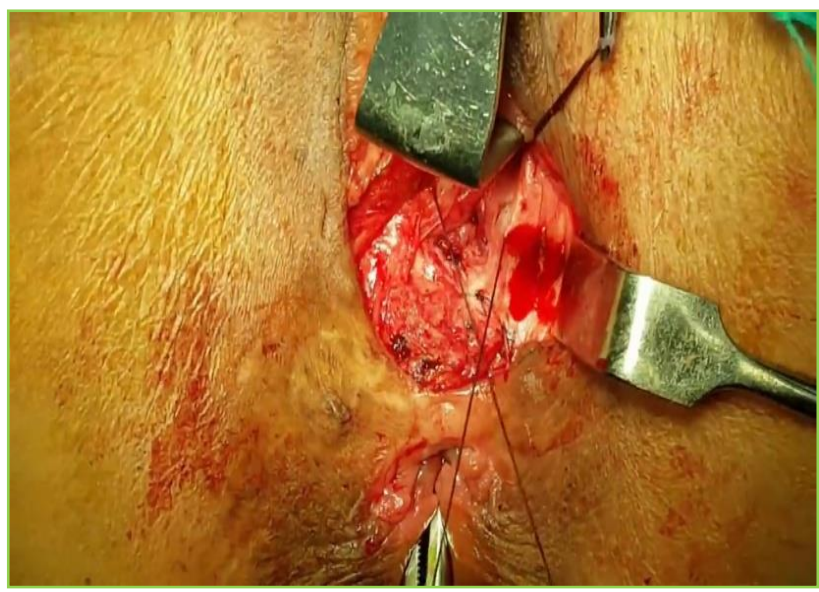

Figure 4: The anterior defect of the IAS extended through the anal mucosa and was plicated with 3-0 polyglactin suture.

Repair of posterior vaginal wall, subcutaneous tissue and skin are done using 2-0 delayed absorbable suture. A rectovaginal examination is performed to confirm complete repair and ensure that all tampons or swabs have been removed. Detailed note is made of the findings and repair. Completion of a pre-designed proforma and a pictorial representation of the tear is done.

\section{Postoperative care}

In the immediate post-operative period,
1: Syrup Lactulose $15 \mathrm{ml}$ thrice daily was given for the first 3 weeks to avoid constipation and to ensure that the patient is having soft stools.

2: Five days of intravenous antibiotics ceftriaxone $1 \mathrm{gm}$ and ornidazole $500 \mathrm{mg}$, both twice a day, were given to all the patient to cover the enteric flora.

3: Sitz bath was given for all the patients twice daily and the patients were allowed to take clear liquids for the first 48 hours and for the next 5 days were put on low residual diet.

4: For pain relief injection diclofenac was used for the first 48 hours for all patients and later on it was used as needed.

5: Patients were mobilized after 24 hours.

On the $10^{\text {th }}$ postoperative day, wound site was examined and resting anal sphincter tone was assessed by digital examination.

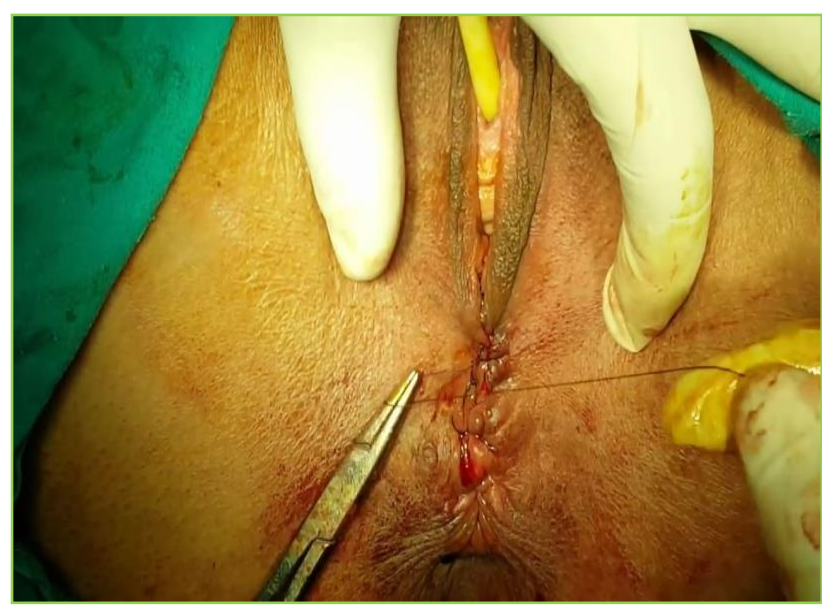

Figure 5: Post-operative image the distance between the posterior fourchette and the anal canal was seen to be lengthened.

\section{RESULTS}

A total of thirty patients underwent CPT repair during the study period. Data analysis was done using SPSS software. Cleveland clinic scoring system (Table1) for fecal incontinence was assessed and surgical repair was recommended to a patient with a score of 12 or greater. $73.3 \%$ of the patients were of age group between 20 and 30 years. All of them were multiparous $.80 \%$ of the patients had deliveries at home, unsupervised and conducted by dais. Nearly $75 \%$ of the patients were completely incontinent, CCIS score of more than 20 (Table 2). $30.3 \%$ were completely ignorant about the disease for more than 10 years and assumed that the symptoms are a result of normal vaginal delivery (Table 3 ). Only about $26.3 \%$ of the patients could recognize symptoms within 5 years of their delivery. 
Table 1: Cleveland clinic incontinence score for the assessment of faecal incontinence.

\begin{tabular}{|llllll|}
\hline & Never & Rarely & Sometimes & Usually & Always \\
\hline Solid & 0 & 1 & 2 & 3 & 4 \\
\hline Liquid & 0 & 1 & 2 & 3 & 4 \\
\hline Flatus & 0 & 1 & 2 & 3 & 4 \\
\hline Use of pads & 0 & 1 & 2 & 3 & 4 \\
\hline Lifestyle alteration & 0 & 1 & 2 & 3 & 4 \\
\hline
\end{tabular}

Complete chronic fourth degree perineal tear is shown in Figure 1. Average duration of surgery was 90 minutes. Figure 5 shows final post-operative image showing reconstruction of the perineal body. 27 out of 30 patients were discharged on post-operative day 10. Three patients went against medical advice on day 3 and were noncompliant to treatment.

Table 2: Degree of incontinence.

\begin{tabular}{|lll|}
\hline Incontinence & n & Percentage \\
\hline Complete incontinence & 22 & 73.3 \\
\hline Severe incontinence & 8 & 26.6 \\
\hline
\end{tabular}

Six months later they came with complaints of fecal incontinence for which re-surgery was done using the same protocol and they had a successful repair. Of the total 30 patients, two patients were lost for follow up. Follow up was done once a month for the first 6 months then once in 3 months for the next one year and then at six monthly interval for a period of 24 months. Overall success rate was $93 \%$ including patients who underwent re surgery for failed repair. All patients were successfully treated and were asymptomatic till the last follow-up.

Table 3: Duration of symptoms.

\begin{tabular}{|lll|}
\hline Duration of symptoms & n & Percentage \\
\hline$<5$ years & 8 & 26.3 \\
\hline $5-10$ years & 13 & 43.3 \\
\hline$>10$ years & 9 & 30.3 \\
\hline
\end{tabular}

Rarely: less than once a month; sometimes: more than once per month or less than once a week; usually: more than once a week but less than once a day.

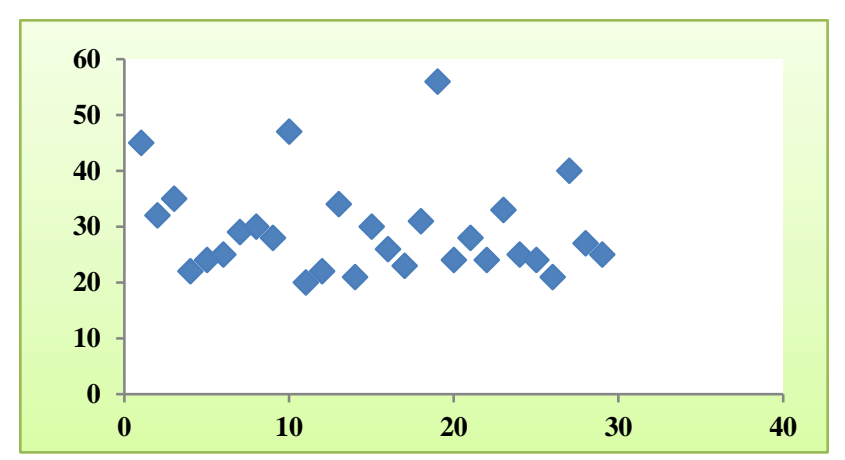

Figure 6: Age distribution of the patients.
Always: more than once a day. CCIS 0, perfect continence; CCIS 1-7, good continence; CCIS 8-14, moderate incontinence; CCIS 15-20, severe incontinence; CCIS .20, completely incontinent.

\section{DISCUSSION}

Perineal injuries are common in obstetric practice. However, CPT is very infrequent. A third or fourthdegree tear (involving the anal sphincter complex) occurs in $0.5-2 \%$. Eighty-five per cent will have a persistent defect of the sphincter despite the immediate (primary) repair by the obstetrician. ${ }^{4}$

However, due to lack of awareness and due to deliveries at home, it can go unnoticed. Though there are very sparse case reports of delayed presentation, large case studies are not reported. This single center study reports thirty cases of chronic fourth degree perineal tear.

The significant finding of the present study was that a secondary repair of an anal sphincter injury was not associated with an unfavourable subjective outcome in relation symptoms of anal incontinence. The incidence of perineal wound dehiscence after repair of third or a fourth-degree perineal tear has been reported to occur in $10 \%$ of the cases. ${ }^{5}$ Several studies gives an estimated complication rate of $15 \%$ for fourth degree perineal laceration repair. Most common complications among them are wound dehiscence, rectovaginal fistula, hematoma, perineal abscess, dysperunia. ${ }^{6,7}$ In the present study there were no such complications noted. All patients underwent repair under optimal conditions in the operating theatre and received pre-operative antibiotics. A good insight of perineal and anal sphincter anatomy, perioperative use of antibiotics and appropriate bowel care all are essential to ensure a successful outcome.

There are no randomized trials reporting the role of prophylactic antibiotics in the management of perineal tears. Even in the ACOG bulletin, this recommendation has been omitted. In present study, $73.3 \%$ of the patients were completely incontinent and $43.3 \%$ had symptoms for the duration between 5 and 10 years. In present study, authors used overlap technique of repair in all patients. This study was not conducted to compare the techniques of repair. There have been several clinical trials that compared the end to end technique with the overlapping technique, but it remains unresolved if one technique is 
superior to the other. ${ }^{4,8,9}$ The success rate in this study is 93.3\% highlighting that a diligently performed operation by a surgeon of adequate expertise likely results in satisfactory results.

In present study $80 \%$ of the patients had home deliveries. There has to be an emphasis that nursing personnel and midwives should be effectively trained so as to manage the second stage to prevent disasters that can significantly affect the quality of life.

Primary repair is exemplary as it is cost effective and significantly improves the overall quality of life. For the patients who are presenting very late and previous failed repairs, Cleveland clinic scoring system for fecal incontinence was assessed and surgical repair was recommended to a patient with a score of 12 or greater an underlying amenable abnormality and gross fecal continence. ${ }^{10-12}$ Improvement in the functional length of the sphincter correlated to a successful outcome .In resourced settings usually an endoanal ultrasound will be performed to know the extent and the type of anal sphincter injury and the pudendal nerve damage. Several previous studies conducted over a long period of time suggest that symptoms of anal incontinence deteriorate over time after repair. However, in the present study symptomatic improvement is seen from 3-6 months of time. Details regarding improvement in the symptoms were evaluated using questionnaire method though many studies suggest that evaluating the symptoms of fecal incontinence should be delayed for at least 12 months. Long term follow-up is thus essential. ${ }^{13,14}$

\section{CONCLUSION}

Authors have reported a large series of CPT repair with a successful outcome. Structured training model for beginners in recognizing and repair of primary tear is beneficial. Secondary repair is usually offered to patients with gross faecal incontinence. The outcome depends on the extent of the anal sphincter damage and associated neurological injuries.

Funding: No funding sources Conflict of interest: None declared

Ethical approval: Not required

\section{REFERENCES}

1. Sultan AH. Anal incontinence after childbirth. Curr Opin Obstet Gynecol. 1997;9:320-4.
2. Sultan AH, Kim MA, Hudson CN, Thomas JM, Bartam CI. Anal-sphincter disruption during vaginal delivery. N Engl J Med. 1993;329:1905-11.

3. Fernando RJ, Sultan AH, Kettle C, Radley S, Jones P, O'Brien PMS. Repair techniques for obstetric anal sphincter injuries: a randomized controlled trial. Obstet Gynecol. 2006;107:1261-8.

4. Fitzpatrick M, Behan M, O'Connell PR, O’Herlihy C. A randomized clinical trial comparing primary overlap with approximation repair of third-degree obstetric tears. Am J Obstet Gynecol. 2000;183:1220-4.

5. Goldaber KG, Wendel PJ, McIntire DD, Wendel GD. Postpartum perineal morbidity after fourth-degree perineal repair. American Journal of Obstetrics \& Gynecology. 1993 Feb 1;168(2):489-93.

6. Venkatesh KS, Ramanujam PS, Larson DM, Haywood MA. Anorectal complications of vaginal delivery. Dis Colon Rectum. 1989;32:1039-41.

7. Pezim ME, Spencer RJ, Stanhope CR, Beart RW Jr, Ready RL, Ilstrup DM. Sphincter repair for fecal incontinence after obstetrical or iatrogenic injury. Dis Colon Rectum 1987;30:521-5.

8. Corman ML. Anal sphincter reconstruction. Surg Clin North Am. 1980;60:457-63.

9. Garcia V, Rogers RG, Kim SS, Hall RJ, KammererDoak DN. Primary repair of obstetric anal sphincter laceration: a randomized trial of two surgical techniques. Am J Obstet Gynecol. 2005;192:1697-701.

10. Williams A, Adams EJ, Tincello DG, Alfirevic Z, Walkinshaw SA, Richmond DH. How to repair an anal sphincter injury after vaginal delivery: results of a randomised controlled trial. BJOG. 2006;113:201-7.

11. National institute of Clinical Excellence (NICE). Faecal incontinence: the management of faecal incontinence in adults. Clinical guidelines CG :49 National Institute for Health and care Excellence (NICE), 2013.

12. Fernando R, Sultan AH, Kettle C, Thakar R, Radley S. Methods of repair for obstetric anal sphincter injury. Cochrane Database Syst Rev. 2006;3:CD002866.

13. Jorge JM, Wexner SD. Etiology and management of fecal incontinence. Dis Colon Rectum. 1993;36:77-97.

14. Tan EK, Jacovides M, Khullar V, Teoh TG, Fernando RJ, Tekkis PP. A cost-effectiveness analysis of delayed sphincteroplasty for anal sphincter injury. Colorectal Dis. 2008;10:653-62.

Cite this article as: Kumar RR, Chigateri S, Kamat L, Divya. Surgical management of chronic fourth degree perineal tear: a single center experience. Int $\mathrm{J}$ Reprod Contracept Obstet Gynecol 2018;7:4919-23. 